\title{
Helen Salisbury: The inverse care law in the digital age
}

\author{
Helen Salisbury GP \\ Oxford
}

A GP friend of mine has a relative in a distant city who is affected by a severe, long term mental health condition. He has evening carers who visit to make sure that he eats at least one good meal a day. They require parking permits, which have to be ordered from the city council. Here the problems begin.

The process is online only and involves filling in a form and attaching multiple documents. My friend asked the council, "What happens if this person doesn't use the internet?"

"That's OK-they can get help with that at the library or Citizens Advice."

"And if they're housebound?"

The person at the council had no more answers. Luckily for this man, he has a sister who navigated her way to the precious permits, but the experience left me and my friend thinking about other, less fortunate people.

Office for National Statistics figures from 2018 showed that $8.4 \%$ of UK adults have never used the internet, including $20 \%$ of disabled adults. Among over $75 \mathrm{~s}$, only $44 \%$ are "recent internet users."

My local clinical commissioning group recently encouraged general practices to ask their patients to complete an online triage form. This would save time because patients would provide comprehensive details ahead of, or even instead of, a telephone conversation. For patients without internet access, reception staff could go through the form with them over the phone. After a few moments in our practice meeting thinking about how difficult this might be and how long it would take, especially for those of our patients with language and comprehension barriers, we rejected the idea as impractical.

ONS figures show that $8.4 \%$ of UK adults have never used the internet, including $20 \%$ of disabled adults
For many patients with busy lives it's a boon to be able to order repeat prescriptions or to book an appointment online, at any time of day or night. They may also welcome video consulting, which could save them, if not us, time. Moving services, benefits, and healthcare access to online platforms may seem efficient and up to date, and it usually works out cheaper than paper or face-to-face processes.

But, without safety nets, these transitions will exacerbate the inverse care law. ${ }^{2}$ The people most in need-elderly people, disabled people, and those who have missed out on education-are the least likely to succeed in accessing the services they're entitled to. It sometimes looks as if designers of patient pathways create models with themselves in mind rather than the likely users. Perhaps picturing their own grandparents, or elderly neighbours, might improve the design process.

So, I'm concerned about the language of the new long term plan for the NHS. ${ }^{3}$ Does a policy of "digital first" imply "analogue second"- and a second best service for those who prefer to phone, write, or visit?

Competing interests: I am a GP partner, I teach medical students at Oxford University and St Anne's College, Oxford, and I answer readers' medical problems for Take A Break magazine. I am also a member of the National Health Action Party and serve on its national executive committee.

Provenance and peer review: Commissioned; not externally peer reviewed.

1 Office for National Statistics. Internet users, UK: 2018. 31 May 2018. https://www.ons. gov.uk/businessindustryandtrade/itandinternetindustry/bulletins/internetusers/2018. Tudor Hart J. The inverse care law. Lancet 1971;1:405-12. 10.1016/S0140-6736(71)92410-X. 4100731

3 NHS England. The NHS long term plan. 7 Jan 2019. https://www.england.nhs.uk/longterm-plan/.

Published by the BMJ Publishing Group Limited. For permission to use (where not already granted under a licence) please go to http://group.bmj.com/group/rights-licensing/ permissions 